\title{
Strategies for Engaging Communities in Creating Physical Civic Technologies
}

\author{
Nick Taylor, Loraine Clarke, Martin Skelly, Sara Nevay \\ DJCAD \\ University of Dundee, UK \\ \{n.x.taylor, 1.z.clarke, m.skelly, s.nevay\}@dundee.ac.uk
}

\begin{abstract}
Despite widespread interest in civic technologies, empowering neighbourhoods to take advantage of these technologies in their local area remains challenging. This paper presents findings from the Ardler Inventors project, which aimed to understand how neighbourhoods can be supported in performing roles normally carried out by researchers and designers. We describe the end-to-end process of bringing people together around technology, designing and prototyping ideas, and ultimately testing several devices in their local area. Through this work, we explore different strategies for infrastructuring local residents' participation with technology, including the use of hackathon-like intensive design events and pre-designed kits for assembly. We contribute findings relating to the ability of these strategies to support building communities around civic technology and the challenges that must be addressed.
\end{abstract}

\section{Author Keywords}

Community; neighbourhood; civic technology; digital civics; grassroots innovation; co-design.

\section{ACM Classification Keywords}

H.5.m. Information interfaces and presentation (e.g., HCI): Miscellaneous;

\section{INTRODUCTION}

As digital technologies once migrated from the workplace to the home, they now increasingly inhabit public spaces in our cities and towns. Although increasing attention is paid to the role of technologies at the large urban scale-for example, creating more efficient public services-less attention is paid to the role that technology can play in neighbourhoods and communities. Mirroring this emphasis on the macro-scale, these technologies are typically determined in a top-down fashion, with little ability for them to be shaped by those most affected by them and less still for citizens to leverage them for their own advantage.

CHI 2018, April 21-26, 2018, Montreal, QC, Canada

(C) 2018 Copyright is held by the owner/author(s).

ACM ISBN 978-1-4503-5620-6/18/04.

https://doi.org/10.1145/3173574.3174081

This work is licensed under a Creative Commons Attribution International 4.0 License
To truly empower citizens in a digital age, we must find ways to meaningfully engage them with shaping and designing these technologies at a grassroots level, to empower them to create technology themselves and to use technology to take collective action.

Our work therefore considers the role of technology at the neighbourhood scale. Neighbourhoods can have distinct identities and may often face unique challenges [32], so it follows that the ways in which neighbourhoods can best make use of technology will vary accordingly. For this reason, HCI research has a long history of considering the role of technology at the neighbourhood scale, often through long-term engagement with neighbourhoods to create meaningful interventions that reflect the unique characteristics of the people and places they are designed for [e.g. 6, 27, 28].

However, our past work has identified challenges around ensuring that neighbourhood-scale technology interventions developed by researchers can be made sustainable, as it is typically difficult to support these research prototypes once projects have ended [30]. Moreover, we must also consider how these findings can be applied or replicated in other neighbourhoods, since most do not have researchers working with them. Towards this end, our current research explores how we can support infrastructuring [4] in neighbourhoods. This entails creating skills, relationships and other environmental factors to support citizens in developing solutions themselves, rather than simply acting as recipients of technology.

In this paper, we describe the Ardler Inventors project, which follows local residents through a year-long end-toend process focusing specifically on physical technology. This involved coming together with researchers and makers, identifying opportunities for technology in their local area, prototyping ideas, then building and deploying refined prototypes. At different stages of this project, we have used different strategies to attempt to support the neighbourhood in their activities, including hackathon-like events and toolkits. We treat this process itself as a prototype, aiming to understand the successes and challenges at each stage of the project, in order to better understand the support that neighbourhoods need in shaping technology for their local area. Through this, we contribute a better understanding of the practical challenges of 
infrastructuring in neighbourhoods, which will support researchers in refining such processes in the future.

\section{BACKGROUND}

\section{Neighbourhoods and Technology}

The role of technology in the geographic communities that exist around neighbourhoods and other geographic spaces has long been a topic of research for $\mathrm{HCI}$ and $\mathrm{CSCW}$. As network technologies proliferated into homes, community networks such as the Blacksburg Electronic Village [6] demonstrated potential for supporting and building a sense of community. Interactive public displays likewise moved from workplaces into truly public spaces, with applications including photo sharing [28], noticeboards and information sharing [7], creating discourse [35], raising awareness of the local area [21] and preserving local culture [1].

More recently, there has been a "civic turn" [18] in HCI, in which neighbourhood-scale technologies have been overtly focused towards engaging or empowering citizens in making positive changes to their environment. Like other neighbourhood-scale technologies, many of these applications have been deployed in public spaces and taken advantage of their physical location, for example by capturing lightweight data from passers-by [e.g. 14, 15, 29, 34]. Other examples of civic technologies in neighbourhoods and communities have included locative apps [13] and citizen sensing [8] and have often been grounded in DIY activities, such as fruit foraging [9], which show citizens taking an active role in shaping their environment.

Common amongst much of this work is the use of participatory design and action research approaches, where local participants play a significant role in defining the shape of the technologies developed. However, the sustainability of these interventions has been called into question [30], since it can be difficult for local residents to maintain or modify prototypes on their own once researchers have moved on. Although strategies have been proposed to mitigate some of these difficulties $[2,30]$, they also make clear the importance of creating skills within the neighbourhood-something necessary for the DIY approaches described above. This gives us cause to consider how we might better create these skills and the circumstances under which neighbourhood residents can create with technology themselves.

\section{Participation and Infrastructuring}

Infrastructuring is a key concept in participatory research, particularly in cases where participants are most actively involved in shaping the project. As a participatory design activity, infrastructuring marks a turn away from creating products and services as outputs of the process, towards instead "identifying, designing and supporting social, technical and spatial infrastructures" [12] that will support future design activities. This infrastructuring supports the creation of publics - a "dynamic organisation of individuals and groups formed by the desire to address an issue" [19] that have the motivations to work together towards exploring issues and perhaps developing solutions. Projects such as Malmö Living Labs [4] have utilised this approach for social innovation over the course of many years.

In these approaches, researchers play the role of friendly outsiders who become "coaches skilled at opening up lines of communication and facilitating research activities with community partners" [16], for example by suggesting appropriate technologies or skills that might be developed [22]. Recent examples of this type of activity at large scale can be seen in the Bristol Approach [3], a project that mobilised citizens across the city around the issue of dampness in homes. Central to this project's approach was the development of a sensor kit and a "city commons" of data and knowledge, in which citizens were invested as owners and producers, not simply as recipients of an intervention designed by researchers. These approaches could also be seen as examples of civic laboratories [32], which call for the democratisation of technology creation to the community and neighbourhood scale.

\section{Widening Participation in Making}

More broadly, our research sits alongside a range of work that aims to widen participation in the creation of technology. Recognising that the world is increasingly shaped by technology, literacy in how these technologies work and how people can shape them themselves is becoming increasingly important. In recent years, there has been a marked effort to support digital fluency [23] using visual programming tools like Scratch or highly scaffolded environments like Apple's Swift Playgrounds. In hardware, platforms like Arduino, Raspberry Pi and BBC Micro:bit aim to simplify the creation of physical prototypes, recognising that the increasing importance of digital technology extends far beyond the screen. Research around such platforms has shown their ability to engage with a much wider audience, for example by greatly simplifying the electronics required [17], enabling the use of a much wider range of materials [5] and by supporting more expressive and creative applications [24]. However, work in this area has also recognised the importance of supportive learning environments in addition to these platforms [20].

Although being able to create using technology is directly relevant to the goals of our project, making is also intrinsically entangled with the types of participation we describe above. Prototyping at different fidelities plays many roles in the design process [26], from focusing discussions, to testing hypotheses and creating new experiences. The ability of people to prototype allows them "to make 'things' that describe future objects, concerns or opportunities" [25]. For this reason, we see tools and methods that enable people to prototype for themselves as an essential part of any attempt to infrastructure participation in design. 


\section{ARDLER INVENTORS}

The research described here took place across the duration of the Ardler Inventors project, which aimed to support neighbourhoods in developing their own civic technologies, especially physical devices in public spaces. Below, we describe the goals of this project and give an overview of its three core activities.

\section{Ardler}

Ardler is a neighbourhood in Dundee, Scotland, located on the northern edge of the city. The neighbourhood was constructed in the 1960s before suffering a period of decline and social issues, until the original estate was demolished in the 1990s and replaced with a smaller number of modern homes and substantial green space. Today, Ardler remains an area of the city with some social and economic issues. Efforts at regeneration continue beyond the replacement of the housing itself, with longterm plans in place to foster social inclusion and community development. A key part of this strategy is the establishment of Ardler Village Trust, a partnership between various local bodies, who saw our project as a potential part of their digital literacy efforts.

\section{Project Overview}

The Ardler Inventors project aimed to explore how neighbourhoods-rather than researchers working with them-could be empowered to take leading roles in imagining, creating and using technology in their local area. Our approach to this was exploring infrastructuring strategies that could be used with local residents, including hackathons to build networks between Ardler and the city's vibrant creative and maker communities and toolkits to provide reusable patterns for civic technologies, culminating in community-led deployments in Ardler. Below, we briefly introduce each of these stages.

\section{Inventor Days}

The project was centred on a series of three day-long hackathon-like Inventor Days [31] spread across six weeks, which were designed to bring together Ardler residents with the city's maker communities. Across the three events, mixed teams worked through a rough design process that involved: exploring Ardler to identify challenges and opportunities in the local area; brainstorming ideas using craft materials; exploring electronics and code to build rough prototypes; and finally fabricating more refined prototypes at the local makerspace. The central aim of these events was to build relationships between the local residents and makers that might facilitate future learning and collaboration between these groups, and secondarily to create excitement and enthusiasm around the possibilities of technology in the local area.

Neighbourhood residents were recruited through attendance at local invents including a summer fair, with the support of Ardler Village Trust. None had any significant experience with technology before the events. Makers were recruited through the city's makerspace, but also through personal connections further afield when uptake was low, and had a mix of technology and craft backgrounds.

\section{Inventor Kits}

In the second stage of the project, we experimented with the creation of a kit that could be used to rapidly build deployable physical computing prototypes. The kits comprised 3D-printed edge pieces and laser cut side and front panels, used to quickly build robust cases and electronics housing. Three complete kits were produced, based on the three concepts that emerged from the Inventor Days, but the system was designed so that it could easily be modified by cutting new front plates, or starting from scratch using pieces of the kits and templates that were provided. The aim of this phase was not to build a production-quality kit, but rather to explore the requirements for such kits, how Ardler residents responded to them and what challenges they faced in attempting to build products using them.

\section{Ardler Deployments}

The final stage of the project involved deploying the prototypes in Ardler. The objective of this stage was again to understand how well-equipped local residents would be to deploy prototypes themselves, having been through the process of designing and building the prototypes. As with this previous stage, we aimed to understand what needs and barriers Ardler residents faced in undertaking this activity. Although we were on hand to provide support, decisions about where to put prototypes and how to introduce them to the neighbourhood were left in the hands of participants as much as possible. Each of the prototypes were left with the participants who built them afterwards.

\section{INVENTOR DAYS}

The three Inventor Days formed the backbone of the project, through which Ardler residents came together, networked with the city's makers, began to think about the role technology could play in their local area and prototyped ideas. These events were attended by approximately a dozen regular attendees, half of whom were from Ardler, with the rest being recruited through the city's makerspace. Throughout the rest of the paper, we will pay close attention to the journeys of two participants, Rebecca and Steve, who remained engaged through the entire process. In this section, we describe how these events were designed, the outputs we saw in terms of both designs and less tangible gains, and the challenges encountered at this stage.

\section{Designing the Events}

\section{Adapting Hackathons}

Hackathons formed the starting point for the design of the Inventor Day events. We particularly aimed to capture their intensive nature and their focus on active participation and creative thinking, as opposed to more discursive consultations. However, we also recognised inclusivity challenges with the hackathon format and made significant changes to cater to a wider audience. Rather than a single 
weekend-long event, we opted instead for a series of three events, each lasting only six hours, which would allow parents and families to attend. The first two events were also hosted in Ardler's community centre, which was intended to remove the need for transport and lower barriers that might stop people attending.

The events were each broadly themed around a different phase of the design process. The first focused on insight gathering around the neighbourhood and identifying challenges and opportunities in the local area, with a strong emphasis on sharing knowledge and building relationships amongst the attendees. The second event followed a more conventional hackathon model, where teams gathered around the ideas that had been invented and began prototyping using a mix of craft materials and simple electronics. At the final event, we moved to the city's makerspace to make use of digital fabrication equipment and build finalised prototypes.

\section{Prioritising Local Knowledge}

A key feature of our adaptations was the aim of prioritising attendees' knowledge and experience of the local area rather than technical knowledge brought by makers. One of the main activities at the first event was a walk around the neighbourhood, where residents gave guided tours to makers. This put them in the position of being the experts rather than the makers coming in with technical expertise. The focus shifted away from technology and onto residents' knowledge of their local area, helping both us and the makers to gain a sense of what Ardler was like. This also removed pressure on the makers to be the creative influence ("I really liked that all the ideas were not coming from my head. I liked that they were coming from people all around me").

Technology was introduced only slowly: at the first event, makers demoed some projects they had worked on, but otherwise there was no direct use of technology. Instead, attendees prototyped their ideas using craft materials, which allowed them to gravitate towards skills and media they were already comfortable with. The use of electronics was only introduced at the second event, where it was introduced as a means of driving forward ideas that people already had, rather than being a driving force itself.

\section{Findings and Outcomes}

\section{Gaining Insights into the Neighbourhood}

One of the main outcomes of the Inventor Days was the insights generated into the neighbourhood. Focusing on learning about Ardler was the starting point for identifying issues and inspiring ideas, which were developed across the remainder of the first day. This occurred firstly through casual gatherings over lunch and then through the afternoon's activities, where participants distilled their observations from the morning into a series of challenges and opportunities, then ultimately a set of ideas that could be taken forward into the second event.

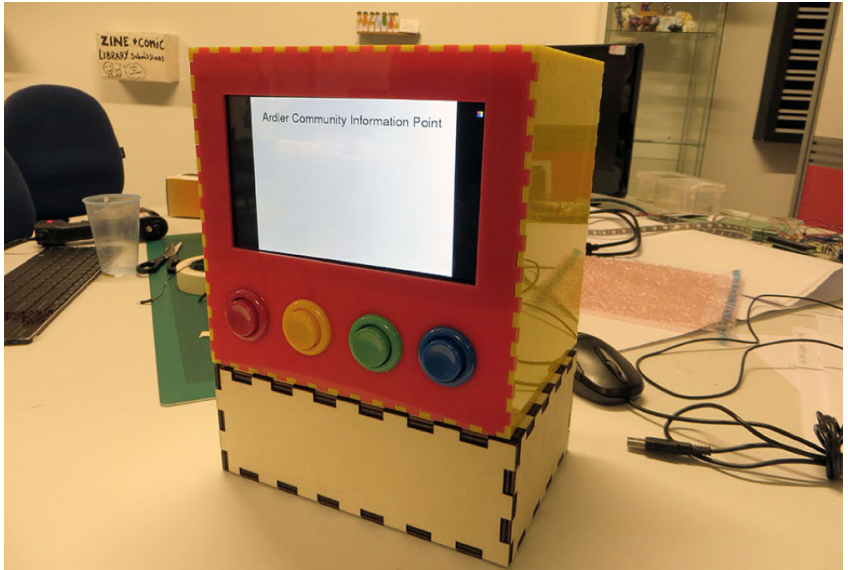

Figure 1. InfoBox prototype after the third Inventor Day.

Many of the insights generated through this exercise, such as problems with traffic or a lack of activities for teenagers, were broadly representative of similar neighbourhoods across the country. However, this process also exposed unique characteristics of Ardler. For example, one group's tour focused extensively on the history of the area, its redevelopment in the 1990s and the things that had been lost in that process, which featured heavily in some of the ideas explored during the afternoon. Other discussions included local legends about witches and crocodiles, a popular Santa's grotto that ran every year in the community centre, and the way that goods circulated around the local area through their charity shop-ideas that would later filter into some of the designs.

\section{Prototypes Developed}

Three main ideas were developed and refined across the series of events. Steve, a father who attended with his son, and Mary, a community organiser, led the development of Info Box (Figure 1), a digital noticeboard to help the neighbourhood to share local information. This was inspired by a worker from neighbourhood's charity shop, who was often asked for information about upcoming events. This was initially prototyped using a small one-line display inside a scavenged plastic box, but was later rebuilt using a Raspberry Pi inside a laser-cut case, with buttons to navigate backwards and forwards through a presentation.

The second prototype, Traffic Trails (Figure 2), was led by Rebecca, a mother who attended with her daughter, and was inspired by issues around traffic safety in the neighbourhood, especially around the schools, which had emerged during the walk around the local area. The idea centred on a trail or roadside device, which would cause children to stop and interact, meaning they did not rush too far ahead of their parents. The final design was a musical toy, but the team imagined that its functionality might change over time to include games and other different interactions.

The final prototype, titled Local Legends, was led by Rebecca's daughter Holly, and focused on the idea of an 


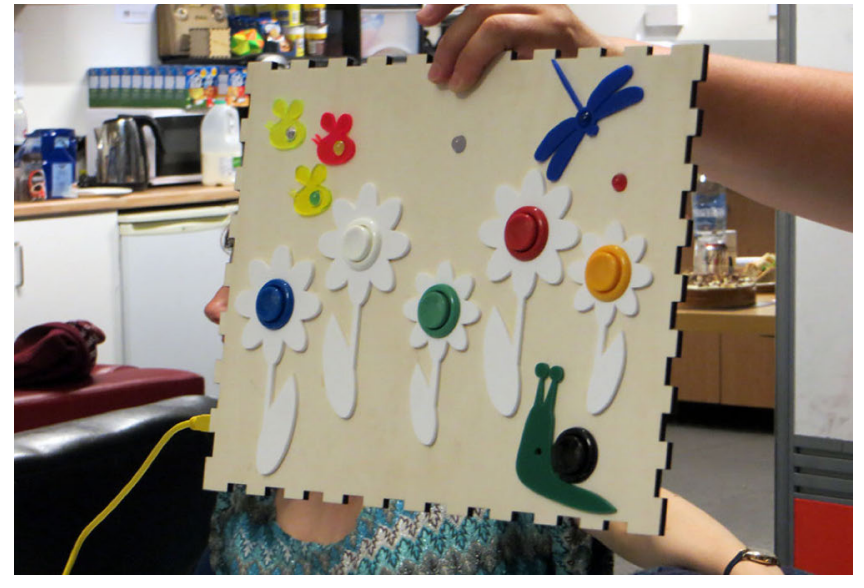

Figure 2. Part of the Traffic Trails prototype.

interactive dinosaur installation, which was inspired by stories and legends told locally. Working with several makers, this was prototyped at different scales, first as a large cardboard dinosaur head with illuminating eyes, then as small light-up dinosaur badges that they discussed being sold around the neighbourhood. The ambition for this design was a large installation in nearby woods, which proved too ambitious to prototype at full scale.

\section{Becoming Comfortable with Technology}

Through developing these simple prototypes, Ardler residents gained insights into the process of developing technology and the skills and materials involved. For many of the participants, the idea that technology was malleable and they could adapt and build it themselves was not something that they had given much thought to ("I've never been interested in computing or building things, or doing anything like that [...] until the Saturday, when I got my hands on the Arduino boards"). Even over a short period of time, attendees gained a much greater appreciation of what was possible, what technologies existed and were surprised at the lack of effort required to achieve tangible results. In many cases, this meant becoming involved directly in coding, either working alongside one of the makers on a shared project, or being tutored and supported in doing so independently.

For some, coding quickly became a new hobby: Steve continued to tinker with electronics between and after the Inventor Days, including buying equipment for his own use and for his son, salvaging components from household objects, and continuing to contact makers for advice. For him, creating with electronics introduced a new activity that he could share with his children. For others, being comfortable with technology did not mean becoming an enthusiastic coder, but still provided a useful set of skills. Rebecca spent most of the second event working on Arduino code, tutored by one of the makers, but later described to us how she regretted spending so much time on this activity, wishing instead that she had the opportunity to explore conductive inks that spoke more to her craft skills.
However, this experience meant that at the subsequent event, she was more confident in being able to explain what she wanted and what role she wanted to play. She was instead able to bring her craft skills to bear, collaborating closely with more technically-minded participants to create a prototype that had much more attention paid to its aesthetics than the other projects (Figure 2).

\section{Infrastructuring Ongoing Activity}

A key measure of success for this first stage of the project was to infrastructure Ardler residents' ability to take forward activities on their own or in co-operation with makers after the events had finished. Although this is something that plays out over a much longer timeframe than our project can account for, we saw indications of onwards activity beginning to emerge.

Between Inventors Days, we saw examples of participants continuing to think about their ideas and how they might be taken forward, including soliciting feedback from other neighbourhood residents and scouting out possible locations for deployments. In these activities, we see participants taking ownership of the ideas they developed and proactively moving them forward. We also saw other types of activity unrelated to building neighbourhood technologies, which still had clear links back to the Inventor Days. In particular, Rebecca made efforts to start a school science club, which had initially emerged as part of a conversation with the local primary school about how they could become involved in the project. As she described: "now that everyone's excited, things just keep popping up”.

However, in terms of building a new network of Ardler residents and makers who continued to engage with each other in making, the events were less successful. Although some communication had continued to take place outside the events, one participant still described the relationship as "a closed book". From the beginning, we struggled to recruit makers from the local area and needed to bring in several participants from other cities. Although the group had bonded well across the events, the project was one of many activities the makers were involved in, and the makerspace's community manager described the many hackathons and other design events in the city that competed for their time. As such, there was less clear motivation for them to stay involved with Ardler after the main series of events had concluded and far fewer of the makers remained involved in the subsequent stages of the project.

\section{INVENTOR KITS}

The Inventor Days had created a new community of engaged participants in Ardler, who had worked together to create a set of ideas and prototypes, while creating knowledge and enthusiasm around technology. By the end of the events, the prototypes had been taken as far as they could be with the skills and resources available to them, but they were still somewhat early prototypes. The second stage of the project explored how this new community could 

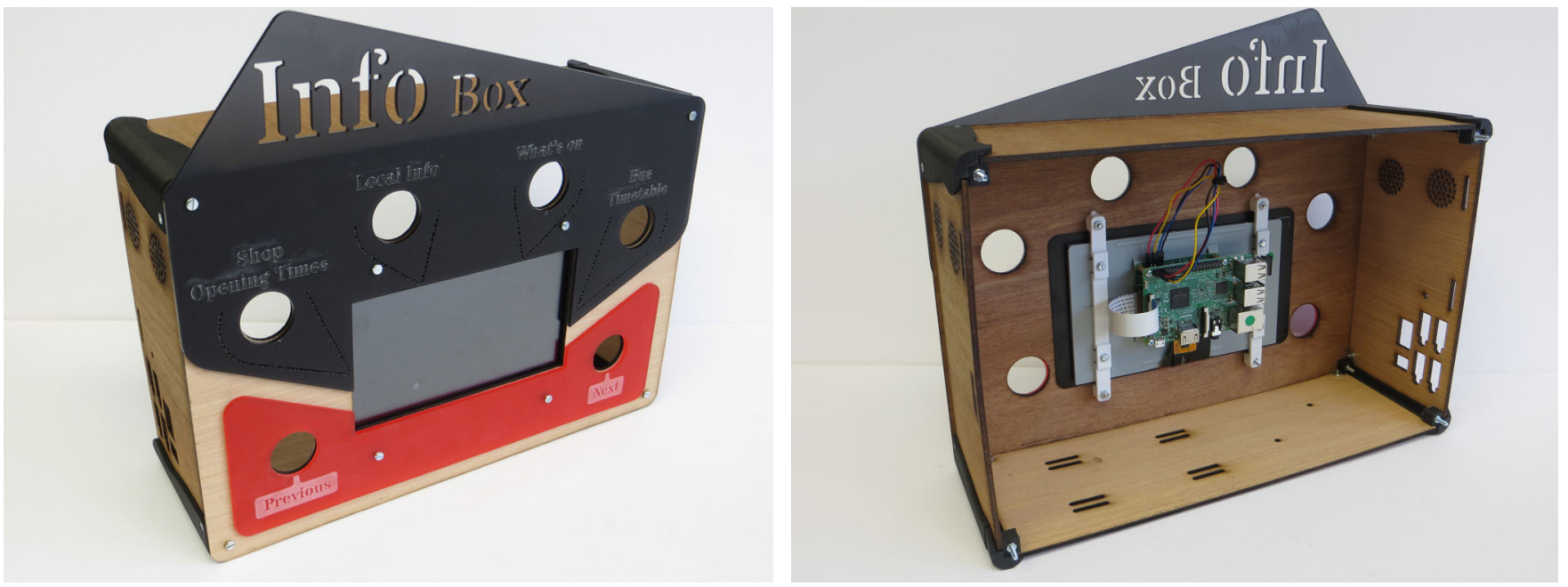

Figure 3. Example of the Inventor Kit used to build the Info Box prototype, before addition of buttons.

overcome that barrier and take the next step towards realworld use and how other neighbourhoods might be able to replicate these designs. To explore this, we developed a set of kits to with two broad goals: firstly, to understand the challenges that they might face when constructing physical civic technologies from kits, and secondly how well such kits might enable them to devise new civic technologies or customise devices for their local area.

\section{Early Input}

In planning the second phase of the project, we wanted to maintain the close involvement of Ardler residents, with a view to them gradually taking on the leading role in the deployments. It was important that they still felt ownership of the designs and involvement in steering the course of the project. Towards this end, we organised several informal gatherings following the Inventor Days, including a showcase of their designs in the neighbourhood and a gathering in our studio to discuss next steps. These gatherings had several goals: to maintain the sense of community that had been established amongst the group, to establish what continuing activities had occurred since the Inventor Days concluded, and to gather feedback on the approach to the subsequent stages of the project.

Throughout this discussion, there was a clear desire for these deployments to happen as an outcome of the project ("if it wasn't kept going, that would be disappointing"). This included a sense that, were the project to end without deployments, it would mean that only the small number of participants would have benefited from being involved, rather than the entire neighbourhood. They also expressed a preference for being directly involved in building prototypes for deployment. Indeed, before our suggestion of a kit was introduced, Steve suggested a similar solution.

The research team were also struck by the level to which participants immediately began to engage with the practical issues around deployments. For example, when talking about the Info Box prototype, Rebecca immediately asked, "is that sustainable?", referring to the need to generate content. This launched a discussion about where content might be sourced from, who might be responsible for this, how they would gain access to the devices and how access could be maintained while also preventing vandalism. The group also immediately saw other purposes for the kit, including opportunities for use in school projects and the after-school club that Rebecca was setting up.

\section{Kit Design}

The overall aim for the kit was that, like a Lego set, it could be used to build a specific device, but that the parts could also be repurposed to build different types of physical civic technology. The kit used a system of plastic edge pieces, which could be combined with side panels to form cases with mounting points for Arduino Uno or Raspberry Pi boards and other electronics (Figure 3). Example devices demonstrated ways of mounting inputs and outputs, including large, tactile buttons, displays, motion sensors and speakers. It was intended that users could mix and match these parts and mountings, as well as adapting the cases for new components. We provided readymanufactured parts, but all the parts were either digitally fabricated (by 3D printer or laser cutter) or widely available standard parts (e.g. screws) so that the templates could be distributed digitally and recreated.

We created three kits based around the three designs generated at the Inventor Days. The Info Box and Traffic Trails kits remained very close to the final prototypes created during the workshops. The Local Legends kit utilised an idea that had been discussed by the team, but not prototyped, in which an interactive dinosaur would respond to movement with sound and lights.

\section{Evaluation Workshop}

To evaluate the kit, participants from the first series of events reconvened for a fourth workshop. Returning attendees included Steve and Rebecca and their children, Mary, the community organiser, and several of the makers. 
In the first part of the workshop, they were given the kits based on their previous ideas to construct. In the second half of the workshop, participants were encouraged to modify the products or explore new ideas that they could rapidly prototype using the kits. The findings below were derived from both our own observations at the event and interviews conducted with participants afterwards.

\section{Responding to the Kit}

Attendees at the workshop responded positively towards receiving the kits and towards the finished products. As had struck us at previous events, such as the meeting in our studio or the showcase in Ardler, there was a strong sense a community that had formed around the project coming back together. There was also a perception of the kits as gifts from the research team and a sense of excitement about the task of building them ("there was lots of, 'it's just like Christmas' happening, we knew we were given something fun to put together").

Ardler residents responded particularly well to the more polished nature of the devices compared to the previous iterations, while still retaining a sense of ownership ("it just looked like this is an actual product now, rather than just something we'd knocked together ourselves, but it's our vision still"). In general, there was a strong sense of achievement, both in terms of reaching the end-point of a process that had played out over several months and in having successfully built the kits into working prototypes over a period of only one or two hours.

\section{Developing New Ideas}

A central goal of the kit was to enable Ardler residents to easily prototype new ideas or modify the devices they had already built. However, although we saw some limited examples of this, they largely saw the devices as finished objects, coming at the end of a long process. Having already iterated over multiple versions of the devices, they were heavily invested in these ideas and generally unwilling to begin the process again: "once we'd done it, complete at that point, and knowing how much work we'd put into making one originally, I just wasn't up for making a new one at that point". This highlights that tools like the Inventor Kits cannot necessarily be separated from the wider programme of activities surrounding them, which was responsible for creating investment in specific ideas.

Despite this, all the groups moved towards this goal in smaller ways. After building the Traffic Trails device, Rebecca conceived a trail of simpler boxes for the nearby woods, which would play different animal sounds. This was partly in response to the complexity of wiring the many buttons and lights on her prototype, but also recalled some of the original greenspace trail ideas from the Inventor Days. Although she did not prototype it using the kit, she did begin to sketch out the idea on paper. There were also examples of small-scale alterations to the existing devices: the Info Box was modified with aesthetic flourishes and later retrofitted with a speaker and used as a jukebox.
After the event, Steve was more vocal about possible modifications and was particularly interested in removing the small screen from the Info Box to create a device that could turn any display into a noticeboard. In general, both the Info Box and Traffic Trails kits were seen as generic enough interfaces that they could be reprogrammed to serve different purposes ("you give somebody a screen and buttons and a box and say [...] that's how you programme it do what you want"). On the other hand, Mary, who had been involved in the Info Box from the beginning, was less interested in modifying the device further, but more concerned about practical deployment concerns.

\section{Technical Ability and Challenges}

The research team paid particular attention to how well participants were able to build the kits and where they needed most support. Constructing the devices themselves was straightforward, but some of the groups were intimidated by the complexity of the electronics inside. The devices were functionally quite simple, but making the internals reconfigurable rather than using custom circuits had led to many wires and connectors. Rebecca talked about the need for much clearer documentation for them to be able to build the kits on their own, even beginning herself to sketch out what these might look like. When problems arose it quickly became clear that troubleshooting skills were particularly valuable. For example, when one of the Info Box's buttons did not work, it required one of the makers to examine the wiring with a multimeter to isolate the problem. Although he had begun to develop basic skills with electronics, Steve did not yet have the experience to tackle these more complex issues.

Although we had expected that replacing the front plate would be the most effective way of modifying the devices, groups who attempted this found it intimidating ("I was looking at it and thinking maybe this is a bit beyond my skill level"). Traffic Trails had an intricate front panel made from multiple overlapping sheets that aimed to recreate the aesthetic of the original prototype. The Local Legends dinosaur was likewise constructed from multiple pieces due to the size of the laser cutter available at the makerspace. The complexity of the front pieces and the vector graphics software used to edit them discouraged them from seeking out other approaches, such as hand-crafting front pieces rather than laser cutting them.

However, we did see some evidence that the skills and knowledge being developed through the Inventor Days process could support further creation using the kit. For example, Steve was confident that he could get parts for the kit printed or cut through online services, which he had done recently for a craft activity with his son. But although the event was in the city's makerspace, participants did not identify this as a means of accessing the machinery they needed. This ability to replicate the kit was an important part of the design, allowing it to be distributed digitally. 


\section{ARDLER DEPLOYMENTS}

Having designed and constructed prototypes, participants displayed a strong desire to see their designs deployed. The final stage of the project aimed to understand how wellequipped they were to do this themselves. At this stage, our primary interest was in the barriers that they would face and what additional support and infrastructuring might be needed. Below, we describe our attempts at public deployments over two separate days. As in other stages of the project, we focus here on the barriers that emerged and the planning that was necessary to overcome these.

\section{Early Planning}

As we have discussed previously, deployment considerations began to emerge early during the process, long before prototypes were built or concrete deployment plans were made. Some of these were very practical matters - such as battery life or fears about vandalism - that the simplicity of the prototypes and kit did not allow them to address. However, participants also spent much time discussing issues including content creation and deployment locations, as well as different ways of approaching the deployment to overcome some of the more practical issues ("I think in the beginning, it might be nice to take it in somewhere inside and let a group of people have $a$ go at it and try and get some feedback").

For the Ardler residents, some clear goals began to emerge. First was a desire to gather feedback on what they had built, with a view to working towards more significant, perhaps permanent, deployments in the future. Secondly, there was a sense of frustration that more people from the local area had not been interested in joining the project and a desire to share it with a wider audience. Sharing what they had built was seen as a way of engaging more people and potentially building interest in being more involved in the future.

\section{Deployment 1}

On the first day of deployments, Rebecca, with her daughter and son, trialled the Traffic Trails and Local Legends prototypes in various outdoor locations around Ardler. Working together, we initially tried to install the devices in a small wooded area in the neighbourhood, as a focus on greenspace in the local area had been present in the design process of both devices. However, we quickly found that plastic ties were unsuitable for securing the prototypes to trees. Instead, we attempted to attach the prototypes to various railings and around Ardler.

Across the day, the most significant challenge was the lack of people on the street who could interact with the prototypes. Even during a school holiday, the streets were relatively quiet, which made it difficult to conduct observations. However, towards the end of the day, they placed the prototypes on railings outside the community centre entrance. This was one of the busiest locations in the neighbourhood, where people frequently waited to meet other people, or passed on the way in and out of the centre. In this location, passers-by would often be attracted by the

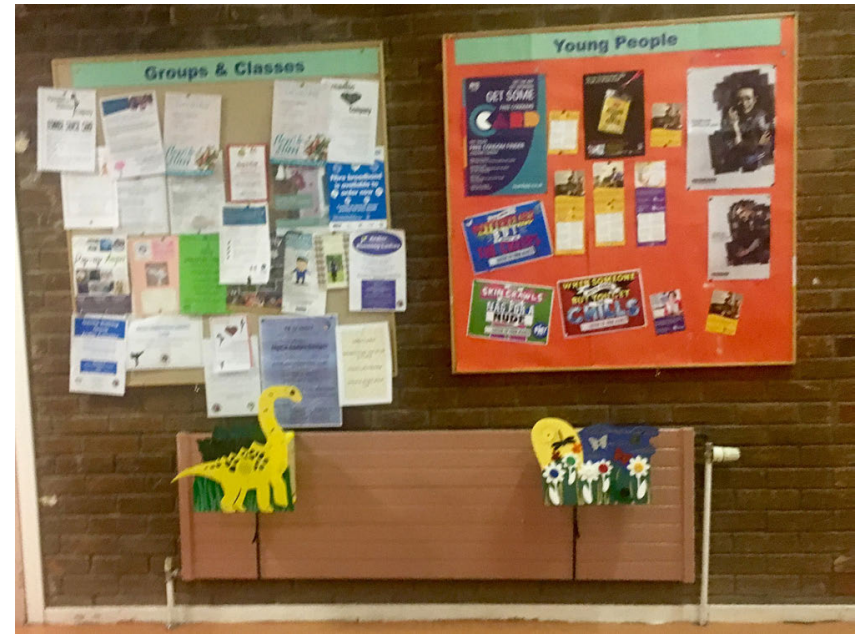

Figure 4. Prototypes deployed in Ardler's community centre.

Local Legends dinosaur, which played dinosaur noises when somebody passed close by, and then stop to interact with the Traffic Trails device, which was more interactive.

A recurring topic in our discussion during the day was discomfort in standing back and watching people interact with the prototypes. As Rebecca described: "It's going to be a bit odd, you know? Waiting for people to come past. I think getting a group and taking it into a group and seeing their reactions would be more immediate." They also noted the strange reactions when people encountered these foreign objects with no context ("everyone's expecting candid camera or something"). Rather, they were most comfortable when directly explaining the prototypes. For example, when somebody who Rebecca knew through their children's school passed by, this led to an extended conversation about the story behind the devices.

\section{Deployment 2}

At the second deployment, both Rebecca and Steve helped to deploy all three prototypes at the local community centre during an annual Fun Day, a popular event that attracts hundreds of visitors from Ardler and nearby areas. During the event, the community centre's main hall is filled with stalls from vendors and local organisations, with activities for children in other rooms. We had originally hoped to conduct deployments outside the main entrance, which is busy during the fair and had been successful previously, but poor weather meant they were located inside the community centre instead.

Having learned about the importance of location from our first attempts, Rebecca spent a lot of time trying to find the perfect location ("it needs to be at a natural stopping place") and was most concerned that it be seen by the largest number of people possible. They were initially placed at the side of a wide corridor at the building's entrance, but after noticing that most people were passing straight by, she wanted to try other locations. After moving them around the corner, they were seen by many more 
people as they moved between the main hall and one of the side rooms hosting children's activities (Figure 4).

This location also provided a seating area where we could observe interaction, but which was close enough to allow them to chat with people about the prototypes, which had been a problem on the first deployment attempt. Rebecca spent a lot of time speaking with passersby, including gathering feedback (e.g. asking a mother "do you think this would stop him on the road?" while her son was playing with Traffic Trails). Due to the nature of the event, this was also an opportunity to show the prototypes to representatives from the city council and other local organisations. For example, one council worker was particularly impressed by the Info Box and thought it would be a good addition to community centres around the city. Throughout, the sense of pride and desire to share their achievements remained strongly evident.

During this time, Steve decided to prototype his idea of a box that could be plugged into a larger display by appropriating a large screen from the community centre and opening the Info Box to access its HDMI port and see how the current content would look on a larger screen. He was happy with the result, which attracted passers-by, although it did not seem clear to them that it was interactive. Unlike Rebecca, he was less interested in gaining feedback or in seeing how the Info Box would work in the wild, but rather saw this as an opportunity to keep tinkering and expanding on the idea he had developed through the previous events.

\section{Handing Over and Ongoing Work}

At the end of the second deployment, both Rebecca and Steve decided to take the prototypes away with them. Rebecca has remained in regular contact, sending regular updates on her craft activities and seeking funding opportunities for her after school club. She had earlier spoken about plans to take Traffic Trails into schools and nurseries that she worked with to get feedback which she has gone on to do in the months following the deployments. Steve, along with Mary, planned to trial the Info Box in Ardler's charity shop, which had been the original use case behind its design. However, at the time of writing, these remained future ambitions. Our own interactions with participants from Ardler have included exhibiting the prototypes at several events in the city, including a major design festival, where both Rebecca and Steve were present to share their work and talk about the project.

\section{DISCUSSION}

Across the three stages of the project, several recurrent themes have emerged that presented obstacles but that also suggest new approaches. Below, we discuss the importance of understanding motivations, supporting ownership and investment, and scaling and maintaining enthusiasm.

\section{Problem Solving and Motivations}

Our approach to this project was about problem solving and giving Ardler residents the tools that they needed to address issues in their local area. However, they often had different motivations. For participants from Ardler, being involved in the project was about enjoyment and personal achievement, while their interest in testing the devices was grounded in sharing what they had built and getting feedback rather than tackling an issue. The importance of motivations was also clear from the relatively low number of local makers and creatives, where the motivations for them to be involved were less clear.

These factors manifested themselves at various stages in the project. At the earliest stages of design, participants strayed away from problems or challenges in Ardler, focusing instead on their lives and experience of the neighbourhood (for example, the walk to school for a parent) where they could use technology creatively to help themselves and others in smaller ways, both functional and whimsical. In the final stages of the project, we can see with hindsight that there was a strong desire from participants for deployments in more familiar and controlled environments. The influence of the research team directed the deployments towards more naturalistic installations in public spaces, of the type that we might normally use for a research project. For local residents, with a different set of goals, this approach was not conducive to sharing their efforts and getting lightweight feedback. For Rebecca especially, the deployment activities as they were originally conceived were of little value, but smaller, more meaningful encounters with other people in Ardler aligned much better with her own motivations.

This suggests to us that HCI needs to move beyond exclusively framing neighbourhood-level applications of technology in terms of problem-solving. While the research taking this approach is incredibly valuable, our findings suggests that less politically charged approaches might engage a different audience with different motivations. Such an approach still empowers neighbourhoods by creating infrastructure in the form of technology-engaged communities with the enthusiasm and skills to apply technology in any way they see fit. Were an issue to arise in the future, these skills and energy could be applied towards such a purpose as well-but they could equally well not be. Likewise, our approach of having residents take on roles we had played in previous projects, replicating our approaches, may need to give way to something different.

\section{Supporting Ownership and Investment}

A recurrent theme across the project has been the sense of ownership that participants felt over the prototypes that they had built. This was best demonstrated by the sense of pride that came across strongly in interviews with participants and in the way that they talked about the prototypes to others. As others have suggested [2], facilitating this kind of investment in the project supports the likelihood of something more sustainable emerging. We can see examples of this longer-term investment and ownership in Rebecca's continuing efforts to gather feedback and in 
Steve's efforts to continue modifying and expanding his prototype. A large part of this was being able to trace the ideas and concepts embodied by each prototype back through the process to their own work. Even when the kits were developed by the research team, they still felt pride in these finished products.

However, it has become clear that the importance of ownership extends beyond just the prototypes and towards the process itself. As we described above, some of the difficulty at the deployment stage emerged when the research team's pre-conceived ideas about how such activities might be structured discouraged Ardler residents from pursuing the types of activities that might have better supported their personal goals and motivations. Where local participants were more invested in the process-for example, being consulted on how we should move from the first to the second stages-we saw more evidence of investment in the outputs from that stage.

This returns us to our core motivation of transferring control from researchers to neighbourhoods, while also reflecting recent calls to support participants in reconfiguring design processes themselves [33]. But it also exposes the paradox that makes this difficult: the participants must take control of the process to be invested in it, but creating a community of invested local residents initially required a carefully designed process. What this suggests is that while the need for some form of bootstrapping is inevitable, the providers of this facilitation should remain aware of their own influence and regularly evaluate the changing role of participants, to ensure that they have direct influence over the process as early and as regularly as possible. Over the course of a long engagement with a neighbourhood, it might be the case that the nature of this relationship changes multiple times.

\section{Scaling and Maintaining Enthusiasm}

We first began recruiting for the Inventor Days a full year before the final day of deployments. Levels of activity varied across the project, peaking around the Inventor Days series, but the number of participants dropped significantly in the second half of the project. The Inventor Days ran with approximately a dozen attendees, split evenly between Ardler residents and makers, but only two core participants and their families remained involved by the end of the project, along with the community manager of the local makerspace.

On the one hand, the small number of participants was not entirely problematic. The small group at the Inventor Days bonded closely in a way that might not have been possible with a larger group. The sense of ownership described above was possible partly because all the participants could be closely involved in one of the designs. But at the same time, the increasingly small number of active participants from Ardler poses a clear problem for sustainability. The loss of many of the makers made the remaining participants increasingly reliant on the research team for technical input, while the sense of energy and comradery that had defined the earlier events was greatly reduced, replaced by individual relationships between participants and the research team. The series of events was difficult to join mid-way through, while the deployments were clearly part of some 'thing' that most residents were not aware of. Points of difficulty arose when trying to interface with the wider neighbourhood, such as the poorly attended showcase and the deployments.

So, although a small group of core participants who can drive projects forward might be beneficial, it became clear that making the type of process we prototyped work will also rely on wider connections across the neighbourhood. In particular, we should consider how activities in the neighbourhood can be made more open, by designing events that support drop-in, lightweight engagement, for example, or by regular work-in-progress exhibitions in the neighbourhood, perhaps organised by participants themselves, as well as the kind of low-key feedback opportunities that Rebecca had favoured. Doing this might put the core participants in a better position to access a wider network of resources. We include the city's makers in this wider halo of resources, but also the participants' personal networks, including schools, groups and other organisations that exist in Ardler. Finally, despite our efforts to minimise the role of researchers, there remains an important role for universities in providing longer-term, lower-intensity support.

\section{SUMMARY}

Providing neighbourhoods with the means to best take advantage of new technologies in their local area is a difficult challenge. Through this research, we have prototyped a series of strategies for engaging neighbourhood residents in different stages of a design process: from gathering insights and prototyping ideas, through to fabricating refined prototypes and conducting deployments to gain feedback. Each of these approaches has shown promise in building the relationships, skills and enthusiasm needed to support future creativity in the neighbourhood. However, we also saw that some of our assumptions about the role of technology and creativity in neighbourhoods were misconceived. Further work must continue to explore how neighbourhoods can better take ownership not just of the technology, but of the processes that develop them.

\section{ACKNOWLEDGMENTS}

This work was funded by the EPSRC/AHRC Hacking for Situated Civic Engagement project (EP/N005619/1) with additional support from RS Components. We would like to thank Ardler Village Trust, Dundee Makerspace and all our participants for their support.

\section{DATA ACCESS STATEMENT}

Anonymised data used in this paper is available upon request from the University of Dundee repository $[10,11]$. 


\section{REFERENCES}

1. Alessandra Agostini, Giorgio De Michelis, Monica Divitini, Maria Antonietta Grasso and Dave Snowdon. 2002. Design and deployment of community systems: reflections on the Campiello experience. Interacting with Computers 14, 6, 689-712. https://doi.org/10.1016/S0953-5438(02)00016-4

2. Mara Balestrini, Jon Bird, Paul Marshall, Alberto Zaro and Yvonne Rogers. 2014. Understanding sustained community engagement: a case study in heritage preservation in rural Argentina. Proceedings of the SIGCHI Conference on Human Factors in Computing Systems (CHI '14), 2675-2684.

https://doi.org/10.1145/2556288.2557323

3. Mara Balestrini, Yvonne Rogers, Carolyn Hassan, Javi Creus, Martha King and Paul Marshall. 2017. A city in common: a framework to orchestrate large-scale citizen engagement around urban issues. Proceedings of the SIGCHI Conference on Human Factors in Computing Systems (CHI '17), 2282-2294.

https://doi.org/10.1145/3025453.3025915

4. Erling Björgvinsson, Pelle Ehn and Per-Anders Hillgren. 2010. Participatory design and "democratizing innovation". Proceedings of the 11th Biennial Participatory Design Conference (PDC '10), 41-50. https://doi.org/10.1145/1900441.1900448

5. Leah Buechley, Mike Eisenberg, Jaime Catchen and Ali Crockett. 2008. The LilyPad Arduino: using computational textiles to investigate engagement, aesthetics, and diversity in computer science education. Proceedings of the SIGCHI Conference on Human Factors in Computing Systems (CHI '08), 423-432. https://doi.org/10.1145/1357054.1357123

6. John M. Carroll and Mary Beth Rosson. 1996. Developing the Blacksburg Electronic Village. Communications of the ACM 39, 12, 69-74. https://doi.org/10.1145/240483.240498

7. Elizabeth F. Churchill, Les Nelson and Gary Hsieh. 2006. Café life in the digital age: augmenting information flow in a café-work-entertainment space. Extended Abstracts on Human Factors in Computing Systems (CHI EA '06), 123-128.

http://doi.org/10.1145/1125451.1125481

8. Carl DiSalvo, Marti Louw, Julina Coupland and MaryAnn Steiner. 2009. Local issues, local uses: tools for robotics and sensing in community contexts. Proceedings of the Seventh ACM Conference on Creativity and Cognition (C\&C '09), 245-254. https://doi.org/10.1145/1640233.1640271

9. Carl DiSalvo and Tom Jenkins. 2017. Fruit are heavy: a prototype public IoT system to support urban foraging. Proceedings of the 2017 Conference on Designing Interactive Systems (DIS '17), 541-553. https://doi.org/10.1145/3064663.3064748
10. Loraine Clarke and Nick Taylor. 2017. Ardler Inventor Days data (interview transcripts and materials generated). https://doi.org/10.15132/10000125

11. Loraine Clarke and Nick Taylor. 2018. Ardler Inventor Days: Stage 3 interview transcripts. https://doi.org/10.15132/10000131

12. Pelle Ehn. 2008. Participation in design things. Proceedings of the Tenth Anniversary Conference on Participatory Design 2008 (PDC '08), 92-101.

13. Andrew Garbett, Rob Comber, Edward Jenkins and Patrick Olivier. 2016. App Movement: a platform for community commissioning of mobile applications. Proceedings of the 2016 CHI Conference on Human Factors in Computing Systems (CHI '16), 26-37. https://doi.org/10.1145/2858036.2858094

14. Connie Golsteijn, Sarah Gallacher, Lisa Koeman, Lorna Wall, Sami Andberg, Yvonne Rogers and Licia Capra. 2015. VoxBox: a tangible machine that gathers opinions from the public at events. Proceedings of the Ninth International Conference on Tangible, Embedded and Embodied Interaction (TEI '15), 201208. https://doi.org/10.1145/2677199.2680588

15. Luke Hespanhol, Martin Tomitsch, Ian McArthur, Joel Fredericks, Ronald Schroeter and Marcus Foth. 2015. Vote as you go: blending interfaces for community engagement into the urban space. Proceedings of the 7th International Conference on Communities and Technologies (C\&T '15), 29-37. https://doi.org/10.1145/2768545.2768553

16. Gillian R. Hayes. 2011. The relationship of action research to human-computer interaction. $A C M$ Transactions on Computer-Human Interaction 18, 3, 15. https://doi.org/10.1145/1993060.1993065

17. Steve Hodges, James Scott, Sue Sentance, Colin Miller, Nicolas Villar, Scarlet Schwiderski-Grosche, Kerry Hammil and Steven Johnston. 2013. .NET Gadgeteer: a new platform for K-12 computer science education. Proceeding of the 44th ACM Technical Symposium on Computer Science Education (SIGCSE '13), 391-396. https://doi.org/10.1145/2445196.2445315

18. Ian G. Johnson, John Vines, Nick Taylor, Edward Jenkins and Justin Marshall. 2016. Reflections on deploying distributed consultation technologies with community organisations. Proceedings of the 2016 CHI Conference on Human Factors in Computing Systems (CHI '16), 2945-2957. https://doi.org/10.1145/2858036.2858098

19. Christopher A. Le Dantec and Carl DiSalvo. 2013. Infrastructuring and the formation of publics in participatory design. Social Studies of Science 43, 2 , 241-264. https://doi.org/10.1177/0306312712471581 
20. David A. Mellis, Leah Buechley, Mitchel Resnick and Björn Hartman. 2016. Engaging amateurs in the design, fabrication, and assembly of electronic devices. Proceedings of the 2016 ACM Conference on Designing Interactive Systems (DIS '16), 1270-1281. https://doi.org/10.1145/2901790.2901833

21. Nemanja Memarovic, Marc Langheinrich and Florian Alt. 2012. The interacting places framework: conceptualizing public display applications that promote community interaction and place awareness. Proceedings of the 2012 International Symposium on Pervasive Displays (PerDis '12), 7. https://doi.org/10.1145/2307798.2307805

22. Cecelia B. Merkel, Lu Xiao, Umer Farooq, Craig H. Ganoe, Roderick Lee, John M. Carroll and Mary Beth Rosson. 2004. Participatory design in community computing contexts: tales from the field. Proceedings of the Eighth Conference on Participatory Design (PDC '04), 1-10. https://doi.org/10.1145/1011870.1011872

23. Mitchel Resnick, John Maloney, Andrés MonroyHernández, Natalie Rusk, Evelyn Eastmond, Karen Brennan, Amon Millner, Eric Rosenbaum, Jay Silver, Brian Silverman and Yasmin Kafai. 2009. Scratch: programming for all. Communications of the ACM 52, 11, 60-67. https://doi.org/10.1145/1592761.1592779

24. Yvonne Rogers, Jeni Paay, Margot Brereton, Kate L. Vaisutis, Gary Marsden and Frank Vetere. 2014. Never too old: engaging retired people inventing the future with MaKey MaKey. Proceedings of the SIGCHI Conference on Human Factors in Computing Systems (CHI '14), 3913-3922. https://doi.org/10.1145/2556288.2557184

25. Elizabeth B.-N. Sanders and Pieter Jan Stappers. 2014. Probes, toolkits and prototypes: three approaches to making in codesigning. CoDesign 10, 1, 5-14. https://doi.org/10.1080/15710882.2014.888183

26. Pieter Jan Stappers, Froukje Sleeswijk Visser and Ianus Keller. 2014. The role of prototypes and frameworks in research through design. The Routledge Companion to Design Research, 167-174.

27. Alex S. Taylor, Siân Lindley, Tim Regan, David Sweeney, Vasillis Vlachokyriakos, Lillie Grainger and Jessica Lingel. 2015. Data-in-place: thinking through the relations between data and community.

Proceedings of the 33rd Annual ACM Conference on
Human Factors in Computing Systems (CHI '15), 2863-2872. https://doi.org/10.1145/2702123.2702558

28. Nick Taylor and Keith Cheverst. 2012. Supporting community awareness with situated displays. IEEE Computer 45, 5, 26-32, https://doi.org/10.1109/MC.2012.113

29. Nick Taylor, Justin Marshall, Alicia Blum-Ross, John Mills, Jon Rogers, Paul Egglestone, David M. Frohlich, Peter Wright and Patrick Olivier. 2012. Viewpoint: empowering communities with situated voting devices. Proceedings of the SIGCHI Conference on Human Factors in Computing Systems (CHI '12), 1361-1370. https://doi.org/10.1145/2207676.2208594

30. Nick Taylor, Keith Cheverst, Pete Wright and Patrick Olivier. 2013. Leaving the wild: lessons from community technology handovers. Proceedings of the SIGCHI Conference on Human Factors in Computing Systems (CHI '13), 1549-1558. https://doi.org/10.1145/2470654.2466206

31. Nick Taylor, Loraine Clarke and Katerina Gorkovenko. 2017. Community Inventor Days: scaffolding grassroots innovation through maker events. Proceedings of the 2017 Conference on Designing Interactive System (DIS '17), 1201-1212. https://doi.org/10.1145/3064663.3064723

32. Anthony M. Townsend. 2013. Smart Cities: Big Data, Civic Hackers, and the Quest for a New Utopia. W. W. Norton.

33. John Vines, Rachel Clarke, Peter Wright, John McCarthy and Patrick Olivier. 2013. Configuring participation: on how we involve people in design. Proceedings of the SIGCHI Conference on Human Factors in Computing Systems (CHI '13), 429-438. https://doi.org/10.1145/2470654.2470716

34. Vasilis Vlachokyriakos, Rob Comber, Karim Ladha, Nick Taylor, Paul Dunphy, Patrick McCorry and Patrick Olivier. 2014. PosterVote: expanding the action repertoire for local political activism. Proceedings of the 2014 Conference on Designing Interactive Systems (DIS '14), 795-804.

https://doi.org/10.1145/2598510.2598523

35. Niels Wouters, Jonathan Huyghe and Andrew Vande Moere. 2014. StreetTalk: participative design of situated public displays for urban neighborhood interaction. Proceedings of the 8th Nordic Conference on Human-Computer Interaction (NordiCHI '14), 747-756. https://doi.org/10.1145/2639189.2641211 